\title{
Comparison of VFA concentration in the caecum of ponies and donkeys
}

\author{
JL Tisserand, B Suhartanto \\ Laboratoire Associé de Recherches Zootechniques INRA-ENSSAA, 26, bd Docteur-Petitjean, \\ 21000 Dijon, France
}

It is generally recognized that donkeys use poor fodders better than horses. In order to explain this phenomenon we have compared the effects of 4 diets all based on wheat straw on the concentration of volatile fatty acids (VFA) in the caecums of donkeys and ponies.

During 4 successive periods each lasting 1 month we distributed the 4 following diets (pelleted in order to avoid the phenomenon of selection) to 3 ponies and 3 donkeys with permanent caecum cannulae (225 and $248 \mathrm{~kg}$ live weight, respectively): 1. SMC: $76 \%$ wheat straw $+16 \%$ maize grain $+8 \%$ soya cakes (cnude protein $(C P)=12.1 \%$ in the dry matter (DM); crude fiber (CF) $=28.9 \%$ DM); 2 . SM: $77 \%$ wheat straw $+23 \%$ maize grain (CP $=7.2 \%$ DM; CF = 29.7\% DM); 3. SMU: $76 \%$ wheat straw $+23 \%$ maize grain $+1 \%$ urea (CP = $10.0 \%$ DM; CF $=29.3 \%$ DM); 4 . S: $100 \%$ wheat straw (CP $=5.8 \%$ DM; CF $=36.9 \%$ DM). During the last week of each period, the caecum content was sampled from each subject just before the morning meal, and 2, 4,6 and $8 \mathrm{~h}$ after in order to measure the concentration in VFA according to the Jouany (1982) method (2 repetitions per animal). At the same time we measured the volume of the caecum content with PEG 4000 (Alrahmoun, 1985) as a marker. For each diet, the differences between the 2 species were analysed by the $t$ test.

Donkeys had a higher DM intake than ponies, except for the SMC diet. The VFA concentration and the volume of their caecum were always higher, which can be related to their higher CF digestibility in the total digestive tract and to the lower $\mathrm{pH}$ of their caecum content. The results suggest a higher VFA production per kg of dry matter intake in donkeys than in ponies.

\section{Alrahmoun W (1985) Thèse d'état, Université Dijon, $213 p$ \\ Jouany JP (1982) Science des aliments 2, 131- 144}

Table I. Dry matter intake (DMI), crude fiber digestibility (dCF) and some characteristics (volume, $\mathrm{pH}$, VFA concentration) of the caecum content of the pony $(P)$ and the donkey (D) fed diets based on straw.

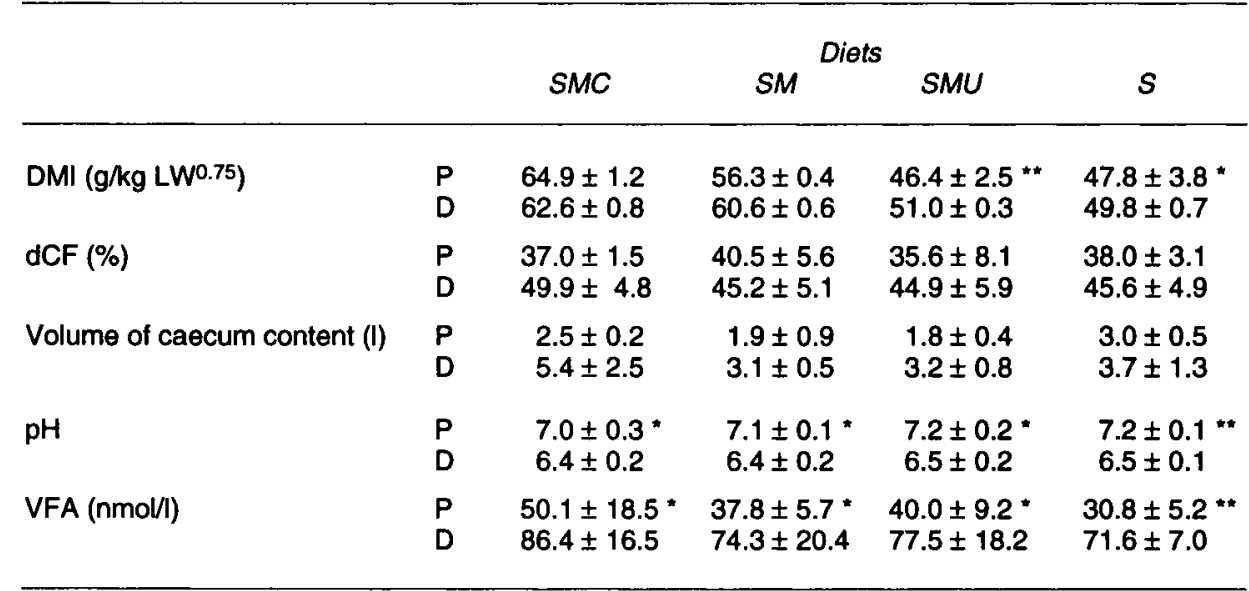

